\title{
Del modelo de desarrollo económico al paradigma del desarrollo humano: una apuesta al papel del arte y las humanidades en el pensamiento de Martha Nussbaum
}

\section{Economic development model paradigm of human development: a challenge to the role of the arts and humanities in the thought of Martha Nussbaum}

\author{
Andrés ARGÜELLO PARRA, Óscar CABEZA HERRERA, Roberto CARDONA \\ OSPINA, Martín HERNÁNDEZ MANRIQUE y Dénix RODRÍGUEZ TORRES* \\ Universidad Santo Tomás, Seccional Bucaramanga, Colombia.
}

Recibido: Diciembre 2011

Aceptado: Mayo 2012

\section{Resumen}

Este documento condensa las reflexiones derivadas del seminario permanente, "Resignificación de las Humanidades en la Educación Superior", realizado por los profesores del Departamento de Humanidades de la Universidad Santo Tomás, Bucaramanga, Colombia, a través de la lectura del libro Sin fines de lucro: por qué la democracia necesita de las humanidades, de Martha Nussbaum (2010). Desde una mirada crítica, se revisa el papel de las humanidades y las artes en el aporte a las democracias que están permeadas, silenciosa y progresivamente, por los modelos de desarrollo económico. Plantea así, una revisión cuidadosa del papel de las humanidades en el contexto de la educación superior.

Palabras clave: Ciudadanía, humanismo, democracia, diálogo, educación.

\begin{abstract}
This document encapsulates the thinking emanating from the permanent seminar: "Resignification of the Humanities in Higher Education" held at the Center for Humanities and Social Sciences at the University of Santo Tomas, Bucaramanga, Colombia, held this time in
\end{abstract}

\footnotetext{
* Comisión redactora delegada por el colectivo de docentes participantes en su seminario de formación permanente, con el objetivo de construir y difundir la reflexión y resultados obtenidos del trabajo adelantado.
} 
the reading book: Not for profit: Why democracy needs the humanities, from the Martha C. Nussbaum (2010). Allows a critical approach to the situation of the humanities and the arts in democracies, silent and gradually permeated by the models of economic development, while eliciting a careful review of the role of the humanities in the context of higher education and moves the action from the humanities at the university.

Keywords: Citizenship, humanism, democracy, dialog, education.

Una pregunta obligada asalta el debate académico actual de aquellos que le apuestan al enfoque de desarrollo humano: ¿cómo realizar el profundo ideal humanista en la era del capitalismo voraz? ese humanismo para ciudadanos del mundo que no sosiega hasta que no confiere sentido a todo, por la búsqueda incesante del logos que se abre camino al descubrimiento de la comprensión, de la interpretación y, por último, de la formación del juicio perfecto que caracteriza a la personalidad madura capaz de tomar opciones fundamentadas.

Las crisis de diversa índole a las que asiste el mundo actual, tocan profundamente la educación y en ella el cultivo de las artes y las humanidades. Consciente de ello, los profesores del Departamento de Humanidades de la Universidad Santo Tomás, de Bucaramanga - Colombia, abordaron el seminario de formación permanente, durante el segundo semestre de 2011, a partir de las claves ofrecidas por Martha C. Nussbaum en su reciente obra: Sin fines de lucro: por qué la democracia necesita de las humanidades, (2010). La autora alerta sobre la existencia de una "crisis silenciosa" debido a que las naciones, "sedientas de ingresos", deciden "desechar" otras aptitudes. Nussbaum (2010) afirmó: "en la medida en que se recorta el presupuesto asignado a las disciplinas humanísticas, se produce una grave erosión de las cualidades esenciales para la vida misma de la democracia" (p.11). Se reconoce entonces el periodo especial de la historia que se vive, donde los cambios a los que se asisten son tan apresurados que no se tiene tiempo para asimilar la "crisis silenciosa" que está de cara a las democracias.

El ámbito educativo, está sometido a tensiones permanentes de acuerdo a los intereses económicos de las naciones y esta tensión representa sin duda las demás tensiones que vive la sociedad, pero paradójicamente sobre lo educativo reposan buena parte de las esperanzas de la sociedad futura. En el ambiente agitado de las sociedades capitalistas, lo importante se centra en los modelos educativos para "la renta", esto es, se potencia una educación para el flujo de mercados y se deja de lado la persona humana como motor de la democracia. Todos -gobiernos, empresas, familias, instituciones educativas- se ven abocados a re-organizarse y a estar en permanente alistamiento para el cambio ante las sugerentes propuestas de las potencias económicas con afán globalizado de lucro; y de esta manera las artes y las humanidades se recortan, se ignoran y se sospecha de ellas dentro de escenarios educativos ocupados en la rentabilidad y la competitividad. 
La crisis expuesta es constatada por Nussbaum en otra de sus obras, El cultivo de la Humanidad (2005), donde expone los desafíos de la educación superior, cuya meta debe ser la de crear una comunidad de personas que desarrollen el pensamiento crítico, que fomenten el juicio crítico más allá de las barreras de clase, género y nacionalidad, que respeten la diversidad y la humanidad. De igual forma, destaca las experiencias exitosas de cursos orientados en universidades como proyectos no curriculares (seminarios y conferencias) destacándose el curso de Amartya Sen sobre hambre y hambruna en Harvard; el curso de Eve Stoddard sobre el cuerpo femenino y estudios globales en ST. Lawrence University; cursos en universidades como la de Brown sobre homosexualidad y derechos humanos, en las principales tradiciones o discusiones orientadas a promover el diálogo civil entre las distintas líneas políticas, en torno a temas profundamente generadores de desacuerdos. Nussbaum (2005), sin embargo, acota que el futuro de estos proyectos es altamente incierto: "enfrentan algunos peligros, sobre todo el de ser socavados por un interés creciente en la educación vocacional, más que en la liberal" (p. 324). En la actualidad, muchos administradores, padres y estudiantes, les parece inútil -dice Nussbaum- aprender para el enriquecimiento de la vida; así instituciones reducen los requerimientos de estudios en humanidades y recortan los planes académicos en el área humanista.

Por otra parte, en Sin fines de lucro, los argumentos conectan exactamente con lo anterior:

Sedientos de dinero, los sistemas nacionales y sus sistemas de educación están destacando sin advertirlo ciertas aptitudes que son necesarias para mantener viva la democracia. Si esta tendencia se prolonga, las naciones de todo el mundo en breve producirán generaciones enteras de máquinas utilitarias, en lugar de ciudadanos cabales con la capacidad de pensar por sí mismos, poseer una mirada crítica sobre las tradiciones y comprender la importancia de los logros y los sufrimientos ajenos. El futuro de la democracia mundial pende de un hilo. (Nussbaum, 2010, 20)

Los argumentos con los cuales soporta esta idea radican en los "cambios drásticos" que a nivel mundial se están dando en el campo educativo: se están erradicando las asignaturas relacionadas con las artes y las humanidades, ya que son consideradas como "ornamentos inútiles" por todos aquellos que defienden políticas estatales que favorecen la competitividad económica global, de ahí que además de perder terreno en los programas curriculares, salgan del corazón y la mente de padres e hijos.

El presente artículo condensa las ideas cernidas en el debate del seminario, desde los aportes ofrecidos por Nussbaum, abordando cuatro categorías centrales para la fundamentación teórica: Ciudadanía y Democracia, Pensamiento Crítico, Papel de las Artes y Desarrollo Humano, alrededor de las cuales circulan otros aspectos debatidos no menos importantes.

El estudio permite a los docentes analizar la crisis advertida por Nussbaum; concentrar la atención en las tareas y servicios académicos de la universidad, de la región y el país; permitirse la autocrítica y movilizarse frente a una realidad que no da 
tregua y que amenaza el ideal de una democracia más humana, donde la universidad tiene el papel fundamental no sólo de cultivarla, sino de defenderla.

Finalmente los aportes registrados, y las ideas expuestas en el presente documento, quedan abiertos al debate socio-humanista en pro de la reflexión permanente que ayude a direccionar y re-significar las humanidades ante los desafíos actuales.

\section{Metodología}

El método que guió la investigación del presente ejercicio en el Departamento de Humanidades fue "El Seminario Alemán" que tiene como objetivo principal no sólo la extensión y profundización de los conocimientos, sino introducirse en los métodos del trabajo y la investigación científicos y familiarizarse con ellos.

Como metodología investigativa, el Seminario Alemán, fue una actividad académica que tuvo su origen en la universidad de Gottingen (Alemania) a finales del siglo XVIII; fue concebido por los universitarios alemanes para sustituir la palabra cátedra y para poder demostrar que es posible unir la investigación y la docencia a fin de que mutuamente se fecunden y complementen.

Para ilustrar los cimientos del seminario alemán, según se han tenido en cuenta en el semestre de discusiones, se puede citar a Friedrich Paulsen:

se ajustan a la naturaleza de la acción académica moderna. No duermen sobre el conocimiento adquirido normal. Buscan inducir el sentido del trabajo científico investigativo y rechazan el achaque consuetudinario de propagar conocimientos adquiridos y por la sola manía de adquirirlos. En los seminarios, los estudiantes aprenden a construir el conocimiento y a prolongarlo. El seminario es para aprender y rotular los métodos. Sólo quien conoce o hace la ruta hacia la fuente del saber, posee pensamiento original y creativo (Paulsen, 1908, citado por Borrero, (2008), 329)

Con la intención de integrar docencia e investigación, según se indicó, el seminario propuso la lectura del libro Sin fines de lucro de Martha Nussbaum (2010), derivado de los trabajos investigativos desarrollados por la autora en los Estados Unidos e India. Se surtieron las siguientes fases:

1. Distribución de los 7 capítulos, entre los 15 profesores participantes, para presentar las relatorías y protocolos en cada sesión: Moisés Araque Ortíz, Andrés Argüello Parra, Gilberto Bonilla Sánchez, Oscar Cabeza Herrera, Roberto Cardona Ospina, Martín Hernández, Miguel López Gómez, Piedad Otero Uribe, Gabriel Ramírez Serrano, Alfonso Rodríguez Balaguera, Dénix Rodríguez Torres, Wilmer Rubiano García, Ernesto Sánchez Jerez, Miguel Ángel Tarazona, Guillermo Villa Hincapié. 
2. Lectura previa de dichos capítulos y desarrollo semanal del seminario.

3. Se facilita a los asistentes copia de la Relatoría preparada y paso seguido, el relator hace lectura de la misma, donde se consigna: número de la relatoría, fecha, lugar, hora, asistentes, desarrollo textual y referencias.

4. El protocolante toma nota de las sugerencias, acotaciones o correcciones que puedan derivarse del texto leído y de los aportes que surgieron en la discusión, para socializarse en el protocolo que abre la sesión siguiente.

5. Se da paso al debate, en un ambiente de reflexión y discusión, donde los aportes individuales son base central para el enriquecimiento del seminario. En algunas ocasiones la discusión se extendió a dos sesiones de trabajo.

6. Finalizado el debate, se anuncia el próximo capítulo en discusión, nombre del protocolante y relator encargados y se da por terminada la sesión.

7. Se archiva en la oficina académica del Departamento de Humanidades, en digital y en físico, todas las relatorías y protocolos.

8. Se compendian las ideas generales en un artículo de autoría colectiva, dedicando algunas sesiones para la confección y revisión del texto, que finalmente se presenta a convocatorias en revistas internacionales.

La metodología del seminario favoreció diversas posibilidades durante el desarrollo de las sesiones: lectura directa de las fuentes primarias y complementarias; ejercicio hermenéutico de los textos; procesos individuales y grupales de lectura y escritura. Tal vez uno de los aportes más importantes, fue el leer a la autora en clave de las Humanidades en la Universidad, como lo ratifica Navarro (2006): "el texto se vuelve pretexto para los más variados desarrollos" (p. 6) y en este caso consistió, en una revisión dialógica de las humanidades desde la mirada de Nussbaum, quien nutre los sentidos al ejercicio docente al tiempo que compromete a investigar ininterrumpidamente la labor desarrollada.

\section{Marco Teórico}

\section{Ciudadanía y Democracia}

El aporte que hace Martha Nussbaum a la re-significación de las humanidades en la formación universitaria, adquiere gran relevancia por el carácter dialógico que invita a incluir miradas diversas para enriquecer y complejizar las grandes cuestiones de la Vida y las múltiples repercusiones para la responsabilidad de las profesiones. A través de esta mirada se puede entender el humanismo como refinamiento de lo humano. 
En la perspectiva de formación integral, entendida como formación para el desarrollo humano, Nussbaum retoma tres grandes conceptos: Condición Humana, Educación y Democracia. Y lanza tres grandes preguntas:

¿Qué tan democrática y participativa es la vida cotidiana en nuestros ambientes educativos? ¿Enseñamos a tomar decisiones, libres desde la responsabilidad y las implicaciones civiles y sociales? ¿Por qué se hace tan difícil conservar las instituciones democráticas basadas en el respeto y en la protección igualitaria de la ley? (Nussbaum, 2010, 52)

Esta reflexión, desde la óptica educativa, plantea para la democracia no una sola lectura (política) sino multivariada y compleja, pues integra diversas dimensiones exigiendo el cultivo de, por lo menos, tres actitudes que permitan dar el giro requerido para el desarrollo democrático del individuo y las sociedades. Primero, una actitud que permita modificar los permanentes tabúes que se manejan en torno a lo jerárquico, pasar al respeto que se fundamenta en la dignidad de la persona y en su saber. La democracia dentro de la Universidad implica mucho refinamiento, se basa en la formación cualificada con el propósito de que las acciones y las palabras consoliden una comunidad académica de saber, de pensamiento, no para homogenizar sino como acceso a las tendencias del saber para una visión plural del mundo. La segunda actitud es la apertura que la democracia permite, porque el conocimiento no se da en una sola vía, sino de forma recíproca y supone una preparación que permita el espacio para "saber recibir", "saber aprender" y "sentir que se necesita a los otros"; en este sentido, la democracia se entiende como un modo de vida para carentes, para gente incompleta que acepta la necesidad de complementarse con los otros y donde el sentido de la condición humana, es el sentido de ser perfectible y educable. Y tercera, actitud dialógica que permite el desarrollo de la idea de sujetos demócratas no como democracia retórica, sino a través de actos evidentes, con respeto recíproco por el otro como ejercicio y proceso democrático.

A propósito de los espacios democráticos, el ejercicio académico de las humanidades es un ejercicio para la paz y los derechos humanos, en suma, para la ciudadanía. Lo que implica asumir una pedagogía de la alteridad que comprende la educación desde el relato y las historias de vida de los sujetos.

Dewey, 1967, y Tagore, 1930, citados por Nussbaum (2010) son muy claros al plantear que la formación integral exige comprender los diferentes tipos de pensamientos, necesidades e incluso expectativas que son incorporados por los sujetos a lo largo de la vida, pues sólo desde allí podemos ser pertinentes en lo que buscamos compartir desde las diferentes disciplinas del conocimiento, especialmente desde las humanidades, ayudando a generar nuevas formas de comprensión que permitan responder a los problemas y exigencias cotidianas del contexto mundial, como lo explicita la filósofa: 
Por un lado, la ciudadanía mundial requiere una gran cantidad de información empírica que puede obtenerse sin necesidad de una formación humanística [...] Por otro lado, para una ciudadanía responsable hace falta mucho más: la capacidad de evaluar pruebas históricas, de aplicar el pensamiento crítico al análisis de los principios económicos y utilizarlos con una actitud equivalente, de evaluar distintas teorías sobre la justicia social, de hablar una lengua extranjera y de reconocer las complejidades de las principales religiones. (p. 130)

La tarea pues, de las humanidades es la constante invitación a deconstruir tradiciones, paradigmas, imaginarios y por supuesto prejuicios, que hacen permanecer en actitudes etnocentristas, donde el otro no cabe, para empezar a visualizar nuevas formas de ver el mundo que permitan reconocer, valorar, respetar y tolerar activamente las diferentes identidades sociales que coexisten en el mundo, como una expresión viva de un multiculturalismo real, acorde a las exigencias de la historia, donde se vaya más allá del discurso por la democracia, a forjar y/o fortalecer actitudes democráticas que hagan posible convivir desde el pluralismo y la biodiversidad presente en el planeta, sin temor alguno de ser perseguido o señalado por "ser diferente".

En este sentido Nussbaum (2010), considera que la escuela puede ayudar a generar los ciudadanos para la democracia si desarrolla la capacidad en el alumno: "de ver el mundo desde la perspectiva del otro, en especial de aquellas personas que la sociedad suele representar como "objetos" o seres inferiores" (p. 73). Si inculca "actitudes frente a la debilidad y la impotencia que den cuenta que ser débil no es vergonzoso y que necesitar a los demás no es indigno de un hombre [...] sino una ocasión para la cooperación y la reciprocidad" (p. 74). Si se convierte en permanente desafío ayudar a "desarrollar la capacidad de sentir un interés genuino por los demás, ya sea que estén cerca o lejos" (p. 74)

Educar para la democracia implica:

"socavar la tendencia a alejarse de las minorías en un acto de repugnancia por considerarlas "inferiores" o "contaminantes (...) enseñar contenidos reales y concretos sobre otros grupos raciales, religiosos y sexuales o sobre las personas con capacidades diferentes, a fin de contrarrestar los estereotipos y la repugnancia que suele acompañarlos (...) fomentar el sentido de la responsabilidad individual tratando a cada niño como un agente responsable de sus actos (...) promover activamente el pensamiento crítico, así como la habilidad y el coraje de expresarlo, aunque disienta de los demás" (Nussbaum, 2010, 74).

Nussbaum termina señalando que este ambicioso plan para ponerse en marcha, implica "gran conocimiento de los problemas sociales y los recursos de cada lugar" (p. 74), sin perder de vista las circunstancias sociales. Es necesario aplicarlo, "no sólo en los contenidos curriculares sino, también en los métodos pedagógicos” (p. 74). 


\section{Pensamiento Crítico}

La "crisis silenciosa" generada por las naciones "sedientas de ingresos", desechan otra aptitud en la formación de las personas: El Pensamiento Crítico, aptitud abordada de manera recurrente en Nussbaum. Se referencia inicialmente como un elemento desaconsejado, aludiendo al poco interés que una educación para el desarrollo económico pone en su cultivo, ya que puede convertirse en una amenaza -así sea de pequeñas élites- si éstas reflexionan relatos sobre la historia social o datos económicos, de donde podrían surgir mayores disertaciones en torno a cuestiones de género, raza o sobre las "bondades" de las inversiones extranjeras para los sectores de la población rural o para la supervivencia de la democracia, donde son perceptibles las desigualdades de oportunidades básicas.

El pensamiento crítico no sería un componente importante de la educación para el crecimiento económico, y en efecto, no lo ha sido para los estados que persiguen esa meta sin descanso como Guajarat, al oeste de la india, conocido por su combinación de alta complejidad tecnológica con docilidad y pensamiento grupal o grouptihink (p .42)

Por tanto la libertad de pensamiento en el estudiante, se torna peligrosa ya que las pretensiones están orientadas a obtener personas o trabajadores obedientes pero altamente productivos, donde el pensamiento crítico será "desalentado" para dar prioridad al trabajo y al rendimiento económico. Comprender la historia, con todos sus horrores y desaciertos, produciría una reflexión crítica del presente, nada conveniente para los intereses económicos de las naciones, que reducirían su historia a los triunfos obtenidos y a las metas globales, ocultando las penosas escenas de injusticias de clase, casta, género, etnia o religión.

Nussbaum (2010) analiza el proyecto educativo propuesto por Tagore en la India, y el gran abismo o desconocimiento total de su ideal con la realidad actual de dicho país; trae a colación una cita del mismo Tagore (1917), aludiendo a la cosificación de las personas emprendido por los planes de crecimiento económico: "el nacionalismo agresivo necesita embotar la conciencia moral, y, en consecuencia necesita personas que no reconozcan lo individual, que hablen una jerga grupal, que se comporten como burócratas dóciles y que también vean el mundo como tales" (p. 46). Por tanto, los humanistas y artistas no comulgan con ese carácter "obtuso" y extienden su imaginación más allá de aquellos modelos habituales que parecen buenos y aceptables.

Por otra parte, la autora aborda el pensamiento crítico en relación con la democracia, ya que resulta fundamental su cultivo si en realidad se procura el desarrollo de una "Democracia humana y sensible" dedicada a promover las oportunidades de la vida, la libertad y la búsqueda de la felicidad. Dentro del compendio de claves que ofrece como estructura de su modelo de desarrollo humano, Nussbaum (2010) insiste en la importancia de inculcar y desarrollar en los ciudadanos aptitudes del orden del pensamiento crítico como: 
[...] aptitud para reflexionar sobre las cuestiones políticas que afectan la nación, analizarlas, examinarlas, argumentarlas y debatirlas sin deferencia alguna ante la autoridad o la tradición; aptitud para emitir un juicio crítico sobre los dirigentes políticos, pero con una idea realista y fundada de las posibilidades concretas que éstos tienen a su alcance (p. 49)

Éstas son algunas de las aptitudes, mencionadas por Nussbaum, para alcanzar un ideal de democracia distinta y con alto desarrollo humano.

En el contexto de una democracia humana y sensible, dice Nussbaum (2010), es fundamental que los ciudadanos tengan independencia de criterio; según lo recalcó Tagore en una conferencia en Japón en el año 1917:

[...] habló de un "suicidio gradual" por encogimiento del alma, y señaló que las personas se dejaban usar cada vez más como engranajes de una máquina gigantesca para llevar adelante sus proyectos del poder nacional. Sólo una cultura pública con gran firmeza crítica podría detener semejante tendencia ruinosa (p. 83)

Lo anterior afirma la necesidad de educar el pensamiento crítico en democracias y sociedades diversas, donde cada quien se haga responsable de sus argumentos y los exponga al debate en el marco del respeto, del disenso y el consenso; la tarea educativa entonces, desde la perspectiva de Nussbaum (2010), ha de hacerse desde las mismas instituciones que encarnen el pensamiento crítico e infundan sus "preceptos en el ethos de la institución misma" y en las metodologías que se aplican en las aulas. De esta manera podría hacerse posible la transmisión de los valores socráticos ${ }^{1}$ mediante la educación humanística, "enseñando a los estudiantes a indagar, evaluar las pruebas, a escribir sus propios trabajos con argumentos bien estructurados y a analizar los argumentos que se exponen en otros textos" (p. 84). La autora recomienda para dar mayor estructura a la argumentación, textos filosóficos como punto de partida, por ejemplo los diálogos de Platón, que invitan a la indagación y la reflexión activa, con el ejemplo de Sócrates como fuente de inspiración.

El pensamiento crítico es, también, contemplado como desafío a la autoridad. En las investigaciones abordadas por Nussbaum (2010), encuentra que en los seres humanos se hallan ciertas "estructuras perniciosas"; en primer lugar, "las personas manifiestan mal comportamiento cuando no se sienten personalmente responsables de sus actos; en segundo lugar, las personas se comportan mal cuando nadie manifiesta una opinión crítica" (p. 72). Dichas conductas fueron manifiestas en los individuos

\footnotetext{
${ }^{1}$ Se refiere a la capacidad de pensar y argumentar por uno mismo, en lugar de someterse a la tradición y a la autoridad. Es decir, la adquisición de la capacidad de la argumentación crítica. P. 76.
} 
estudiados por $\mathrm{Asch}^{2}$, quienes se sumaban al juicio erróneo cuando coincidían en el error todas las otras personas que ellos tenían como pares y que trabajaban para el investigador, pero si una de estas personas desistía, resultaba suficiente para hacer caso a su propia percepción y su propio juicio. Nussbaum traslada estos resultados en un análisis en el contexto de la educación básica, ya que los procesos de educación pueden alterar fácilmente el sentido de la responsabilidad individual, tender a concebir a los otros como entes de control que anulan la voluntad de manifestar opiniones críticas.

Es posible ver el gran papel que juega la escuela y la familia, en el cultivo del pensamiento crítico, ya que la escuela puede reforzar o disminuir lo que se ha aprendido en casa. Dentro de las tareas acuciantes de la escuela, que señala Nussbaum (2010), es posible identificar algunas relacionadas con el pensamiento crítico, por ejemplo cuando postula: "la escuela puede promover activamente el pensamiento crítico, así como la habilidad y el coraje de expresarlo, aunque disienta de los demás" (p. 74), para ello son necesarias instituciones y maestros unidos en el mismo empeño y con el gusto y la habilidad para fomentarlo no sólo en los contenidos curriculares sino desde los mismos métodos pedagógicos desarrollados.

Desde un juicioso análisis del Método Socrático, Nussbaum, ofrece un singular abordaje al pensamiento crítico, evocando el valor mismo de la argumentación, según lo proclamara Sócrates, como un valor para la democracia. Desde esta perspectiva, reconoce la filósofa lo distante que se halla la sociedad actual del ideal socrático, en un mundo "decidido a maximizar el crecimiento económico"; sostiene Nussbaum (2010) que muchas personas consideran: "que se puede prescindir de la capacidad de pensar y argumentar por uno mismo, si se busca un resultado comercializable que pueda cuantificarse" (p. 76). Las mismas evaluaciones, han de modificarse para medir la capacidad de argumentación crítica, desde el diseño de una evaluación cualitativa que revise la interacción en el aula y los escritos del alumno, pero los exámenes estandarizados no contemplan dichos parámetros puesto que sus intereses son otros.

La falta de autoexamen deriva en diversos problemas que puede dilucidar Nussbaum (2010), uno de ellos es que no hay claridad respecto a los objetivos que las personas se trazan y más aún si se trata de tomar decisiones difíciles, si se trata de saber qué se quiere o importa:

Si bien ese autoexamen permanente que propone Sócrates no garantiza que los objetivos sean buenos, al menos garantiza que serán comprendidos con claridad en sí mismos y en su interrelación y que no pasarán por alto cuestiones fundamentales debido a la prisa o por accidente (p. 78).

Un segundo problema, con las personas que no hacen examen crítico de sí mismas, es que con frecuencia resultan demasiado influenciables, la retórica de un orador puede llevarlos de un lado para otro:

\footnotetext{
${ }^{2}$ Investigaciones de Milgram y Salomon Asch, resumidas por Philip Zimbardo. Citada por Nussbaum, M. (2010) Sin Fines de lucro. p. 72.
} 
cuando se pierden de vista los argumentos, las personas se dejan llevar con facilidad por la fama o el prestigio del orador, o por el consenso de la cultura de pares. El autoexamen crítico que propone Sócrates, en cambio no es autoritario en lo más mínimo. El estatus del orador no importa, lo que importa es la naturaleza de su argumentación (p. 79)

Finalmente, Nussbaum (2010) halla otro problema, y es que las personas que viven sin reflexión suelen tratarse de manera irrespetuosa; constatable en las contiendas políticas, donde se toma partido y se llega hasta la agresión al bando contrario, no se piensa la posibilidad mínima de llegar a un punto común. Por eso puntualiza la importancia y necesidad del autoexamen, pues "esa actitud crítica revela la estructura de posición que adopta cada uno, al tiempo que exhibe los preconceptos compartidos y los puntos de intersección que pueden ayudar a los ciudadanos a avanzar hacia una conclusión común" (p. 80).

Como ejemplo de vida examinada, Nussbaum recuerda como Dewey siempre estuvo inspirado en el pensamiento socrático, ya que su aporte a la democracia fue concepto de compromiso crítico y racional. Según Dewey, dice Nussbaum, el problema central de los métodos educativos convencionales es la pasividad que "engendra" en los alumnos; las escuelas no priorizan el análisis, la indagación y la resolución de problemas. Cuando se busca que los estudiantes sean pasivos oyentes, no sólo se les castra el desarrollo de sus facultades críticas, sino que se les debilita, y la democracia necesita ciudadanos en "estado de alerta". Dewey propendía porque el aula fuera un espacio del universo real, donde se debatieran problemas de la vida misma y se recurriera a aptitudes prácticas más concretas, por lo tanto para Nussbaum (2010): “el elemento socrático no se limitaba a las capacidades intelectuales, sino constituía un aspecto de las capacidades prácticas: era toda una postura frente a los problemas de la vida real" (p. 97). Todo esto era posible en un ambiente de comunicación abierta y democrática, lejos de la imposición de autoridades externas, simplemente acatando la guía de los maestros. Tanto en su obra El cultivo de la Humanidad (2005) como en Sin fines de lucro (2010) la filósofa insiste en la necesidad de vivir bajo el cultivo de una vida examinada, como una capacidad que debemos desarrollar al mejor estilo socrático, para vivir en una democracia más humana.

El desarrollo del pensamiento crítico, entonces, establece relación con la educación para la ciudadanía mundial, ya que los alumnos en la educación superior necesitan desarrollar sus capacidades como ciudadanos del mundo con mayor grado de complejidad. El pensamiento crítico es un imperativo necesario, debido a que los alumnos deben examinar, por ejemplo, culturas ajenas que los lleven a conocer profundamente la historia y tradiciones de tales culturas,

sólo así, pueden reconocer de qué modo las diferencias de clase, casta o religión generan diferentes oportunidades de vida, en qué se distingue la vida urbana de la vida rural, cómo dependen las oportunidades urbanas de la organización política e incluso de qué manera se pueden modificar la organización familiar y los roles femeninos y masculinos mediante las políticas de gobierno y las leyes (p. 128). 
Por lo anterior la autora se plantea el siguiente interrogante ¿es realmente cierto que la ciudadanía mundial necesita la formación humanista? En lo que compete a pensamiento crítico es categórica al afirmar que, para una ciudadanía más responsable se necesita aplicar el pensamiento crítico al análisis de los principios económicos y utilizarlos con una actitud equivalente, de revisar distintas teorías sobre la justicia social, de hablar una lengua extranjera y de reconocer las complejidades de las principales religiones. Para Nussbaum (2010): "sólo así desde esta perspectiva humanística y crítica, será posible formar ciudadanos del mundo inteligentes" (p. 130).

El desarrollo de la capacidad de pensamiento crítico es una preocupación latente de la autora y advierte, sin tapujos, que con la desaparición del pensamiento crítico en las escuelas y la concertación generalizada para dedicarse a la formación técnica, se ve claramente, "cómo se puede transformar a un conjunto de ingenieros dóciles en una fuerza asesina, capaz de implementar las políticas racistas y antidemocráticas más horrendas que se pueden imaginar" (p. 188), de allí la importancia en insistir en las artes y las humanidades que, aunque no den dinero, contribuyen al proceso de ser más humano, donde cada uno se valora y respeta al otro, reconoce su diversidad de pensamientos y sentimientos y aporta a la consolidación de naciones capaces de superar el miedo y la desconfianza en pro de un debate signado por la razón y la compasión.

\section{Las artes y humanidades para la formación de la democracia}

A través de la lectura y reflexión de Nussbaum, se evidencia la importancia y el sentido que la escritora norteamericana da a las artes y a las humanidades como elementos fundamentales en la formación de la democracia y como herramientas útiles en la educación del ser humano en todos los niveles.

Son ellas quienes desempeñan una función central en la historia de la democracia; puesto que ya nos encontramos en una crisis silenciosa, que es la pérdida cotidiana de las cualidades esenciales de la misma democracia, el explorar en estas dimensiones del arte y las humanidades, contribuye a imaginar la situación de otros seres humanos y ayuda al cultivo interior; ellas constituyen el cimiento de la ciudadanía, según lo expresa Ruth O'Brien en el prefacio del libro de Nussbaum (2010): “el descuido y el desprecio de las artes y las humanidades generan un peligro para nuestra calidad de vida y para la salud de nuestras democracias" (p.13).

Este derrumbe de la democracia, parte de la misma crisis mundial en materia de educación y vistas las artes y las humanidades como no apreciables en el concierto de la economía global, son vulnerables y potencialmente extintas de toda clase de formación académica: "Las artes y las humanidades [...] concebidas como ornamentos inútiles por quienes definen las políticas estatales en un momento en que las naciones deben eliminar todo lo que no tenga ninguna utilidad para ser competitivas con el mercado global" (p. 20). 
La exclusión de las artes en la educación para generar renta es, según Nussbaum, olvidarse del alma del otro, es ignorar ese acercamiento a ese otro como una persona, un ser humano y convertirlo en un objeto para fines distintos: "democracia: respeto e interés por el otro, que a la vez se fundan en la capacidad de ver a los demás como seres humanos, no como meros objetos" (p. 25). Se ve entonces, de nuevo, a la democracia destinada al fracaso.

Las artes y las humanidades son fuente de imaginación y creatividad, generan un pensamiento crítico frente a la realidad, a la vez que generan empatía alrededor de diferentes experiencias humanas y hacen que lo complejo del mundo sea entendible y respetable en las diferencias, es precisamente allí donde se enriquece el espíritu y se potencializan las capacidades de apertura para ser ciudadanos del mundo.

Si el bloque económico que quiere arrasar con las humanidades y que teme precisamente que las personas "despierten" su sentir por medio de las artes, se diera cuenta que son ellas un eje esencial para fomentar un clima de creatividad innovadora y de administración responsable de los recursos, probablemente se formaría una sinergia de desarrollo humano que no rivalizaría con la ciencia y la técnica:

[...] los especialistas en educación para el crecimiento económico no se limitan en hacer caso omiso de las disciplinas artísticas y humanísticas. En realidad, les tienen miedo, pues el cultivo y el desarrollo de la comprensión resultan especialmente peligrosos frente a la moral obtusa, que a su vez es necesaria para poner en práctica los planes de crecimiento económico que ignoran la desigualdad (p. 46).

Es necesario el arte y la literatura, que propendan por la estética, convirtiéndose en ambientes agradables para el aprendizaje de la vida; el arte genera sentimientos, interroga lo repugnante y adiestra la empatía y la reciprocidad; invita a comprender las ideas ajenas y a buscar criterios propios, produciendo así nuevos conocimientos: "[...] la educación humanística fortalece las capacidades de la imaginación y la independencia de criterio, que son fundamentales para una cultura innovadora" (p. 82).

Estos nuevos conocimientos se fortalecen con su respectiva argumentación, el arte de argumentar es el arte de humanizar al "otro desde sí", debatiendo ideologías, compartiendo tesis, creando imaginación y comprensión de lo contrario, además que genera una resolución pacífica de las diferencias, en otras palabras, es hacer ejercicio de la democracia. La argumentación es el momento en el que se imagina y posee un criterio definido, es donde se pueden crear e innovar de modo responsable las propias ideas y por ende los actos generados por el pensamiento.

Frente a este reto de hacer una pedagogía socrática, los pedagogos dan pasos importantes en la consecución de una acertada pedagogía para que el niño sea creador de su propio pensar. Rousseau y su obra Emilio, Pestalozzi y su novela Leonardo y Gertrudis, son referentes paralelos en dar importancia a la empatía y el afecto, utilizando figuras de tutor y figuras maternales en la educación de la infancia, al tiempo que se interesan en cultivar sus capacidades emocionales. Froebel, por su parte, llega con un ingrediente importante, el juego y el afecto, las actividades lúdicas como 
pilar de apoyo, donde el niño tiene la posibilidad de ejercitar las bases de la democracia. Finalmente, Tagore ayuda a comprender la importancia central de las artes para el desarrollo pleno de la personalidad.

Tagore es un ejemplo que rompe paradigmas de la educación tradicional, transforma esquemas y despierta con el arte nuevos imaginarios y la sensibilidad ante lo real, él utiliza la transversalidad de las artes y humanidades en el currículo de su universidad $^{3}$, donde la danza, la pintura y al literatura son el verdadero goce de la educación. El arte es la continuidad del juego iniciado en la niñez "en efecto, las artes otorgaban al niño nuevas capacidades para comprender su propia persona y la de los demás" (p. 139).

Para terminar este recorrido, en la importancia de este eje de las artes y las humanidades en la educación y dar el primer paso a una nueva significación de la democracia, es primordial contar con una mente flexible, abierta y creativa. "Las artes estimulan el cultivo del propio mundo interior, pero también la sensibilidad ante los otros" (p. 141). Sin duda, las artes tocan las fibras más profundas del yo y descubren y entienden al otro como un potencial que se puede educar.

\section{Desarrollo Humano}

Martha Nussbaum inicia su reflexión sobre el desarrollo preguntándose “¿qué significa entonces el progreso para una nación?" (p. 34), a lo cual responde mostrando que la tensión presente en este tema, en cuanto la elaboración de políticas para el desarrollo desde el Fondo Monetario Internacional (FMI) y el Banco Mundial (BM), es visto sólo como un indicador económico que califica la calidad de vida de un país en la medida que incrementa su producto interno per cápita, así se deje de lado la distribución y registre niveles alarmantes de desigualdad (p. 41). Pero el desarrollo humano examinado desde "los otros aspectos de la calidad de vida que no están vinculados con el crecimiento económico" (p. 34) tales como la salud, la educación, la libertad política, la igualdad social, la estabilidad democrática, la calidad de las relaciones de género y raza, no están asegurados por la suerte económica (p. 35) de un país, pues:

[...] al estudiar los resultados de cada uno de estos experimentos hemos descubierto que el viejo modelo no deriva de manera concreta en esos beneficios [...], en los últimos tiempos el crecimiento económico tiene gran aceptación y, en todo caso, la tendencia apunta a confiar cada vez más en el "viejo modelo", en lugar de buscar una descripción más compleja de lo que debería tratar de lograr cada sociedad para sus integrantes ( $\mathrm{p}$. 36).

\footnotetext{
${ }^{3}$ Se refiere a la universidad Visva-Bharati (en español, "todo el mundo") fundada por Rabindranath Tagore. Actualmente pertenece al gobierno y funciona como cualquier otra universidad de disciplinas únicas, con el principal objetivo de posicionarse en el mercado. P 40.
} 
Tanto en Estados Unidos como en la India, países objeto del estudio de Nussbaum, no se logra discernir la adopción del paradigma de desarrollo humano, en cuanto no es claro si hay reformulación de políticas inclinadas al desarrollo humano o solo es la simple aplicación de algunos elementos de redistribución pero en el marco del modelo de crecimiento económico. No es la excepción para la Universidad Visva-Bharati, fundada en la India por Tagore con el modelo interdisciplinario de las artes y las humanidades, y que hoy funciona disciplinarmente con el objetivo de posicionarse en el mercado y para los exámenes estandarizados a nivel nacional (p. 40).

Por tanto, "la educación para el crecimiento económico se opondrá a la presencia de las artes y las humanidades como ingredientes de la formación elemental mediante un ataque que, hoy en día, se puede observar en todo el planeta" (p. 47), en tanto que los países "siempre y cuando generen una élite competente para la tecnología y los negocios" (p. 42) parecieran entonces no preocuparse demasiado por la distribución y la igualdad al acceso educativo. En esta perspectiva es fácil concebir que "un país puede crecer sin dificultades aunque los sectores más pobres de la población rural sigan siendo analfabetos" (p. 41). Ahora, lo más paradójico es que en este momento de crecimiento económico, para prosperar en un ámbito empresarial más dinámico "hace falta contar con una mente flexible, abierta y creativa" (p. 151) capacidades éstas para la innovación, que a todas luces han de acompañar las competencias de la formación profesional estricta. Así "si nuestro único interés fuera el crecimiento económico nacional, también deberíamos proteger la educación artística y humanística" (p. 152).

Frente al argumento que se viene desarrollando, "¿qué otras alternativas existen para concebir el tipo de naciones y de ciudadanos que pretendemos formar?" (p. 47). Nussbaum propone el paradigma del desarrollo humano (p. 47), en el cual la prioridad está en las oportunidades o -capacidades- propias a cada persona y el respeto por cuenta de las leyes e instituciones de la dignidad humana inalienable. "Toda nación mínimamente decente debería aceptar que sus ciudadanos están dotados de ciertos derechos, en esas esferas y en otras, y debería elaborar estrategias para que superen determinados umbrales de oportunidad en cada una de ellas" (p. 47). Estas esferas abarcan la vida (en sentido amplio), la integridad física, la salud, la educación, las libertades políticas, religiosas, sindicales, la expresión, el género u orientación sexual, así como la participación política. "El modelo de desarrollo humano no es una quimera idealista, sino que se encuentra estrechamente vinculado con los compromisos constitucionales, a veces incumplidos, de casi todas las naciones democráticas” (p. 48).

Favorecer en la educación las disciplinas artísticas, y la lúdica en un niño, agencia la capacidad de admiración, asombro e interés genuino por la vida de otro (p. 136), esta última amparada en las capacidades de: a) superar la dependencia narcisista (p. 67), b) el "concebir el mundo como un lugar en el que uno no está solo" (p. 133), y c) el imaginar cómo puede ser la experiencia del otro (p. 134), para comprender el sufrimiento, la indefensión, la impotencia, la vergüenza, la repugnancia y vulnerabilidad del sujeto humano (p. 68). Así, se contribuye con "el desarrollo de actitudes sanas en la amistad, en el amor y, más adelante, en la vida política” (p. 136) 
de toda civilización, en el entendido que se está formando un ciudadano para la vida en sociedad, en la cual "siempre existen algunas personas que están dispuestas a vivir con las demás en condiciones de respeto mutuo y reciprocidad, y otras que se confortan con la dominación" (p. 53). El reto está en formar más ciudadanos del primer tipo que el segundo.

Así para Nussbaum, la propuesta inicial para el modelo de desarrollo humano, ha de favorecer e inculcar en sus ciudadanos las aptitudes de: a) reflexión autónoma sobre las cuestiones políticas, b) reconocimiento del otro como fin en sí mismo, no como medio, y con los mismos derechos, c) interés por la vida de los otros ciudadanos nacionales y mundiales, d) capacidad de imaginar las cuestiones complejas que afectan el desarrollo de una vida humana, e) juicio crítico sobre los dirigentes políticos, f) disposición para pensar el bien común de la nación, y g) deliberación trasnacional inteligente al concebir la nación en un orden global. (p. 49).

\section{Hallazgos}

El trabajo del seminario de investigación, siguiendo la metodología ya expuesta, permitió al colectivo de profesores del Departamento de Humanidades llegar a los siguientes hallazgos de la situación actual de la humanidades, específicamente en su articulación al contexto de formación universitario colombiano y por extensión, de América Latina, en el cual han de vérselas con las experiencias pedagógicas, los desafíos del mundo actual, las sociedades del conocimiento, el multiculturalismo, la globalización económica, el neoliberalismo y su tendencia capitalista a instrumentalizar el servicio educativo, para lo cual la reflexión crítica, la deconstrucción de los modelos de la modernidad centrados en la racionalidad y la pregunta por la re-significación de las humanidades, ha de promover la relación armónica entre sujetos-naturaleza-sociedades y culturas.

Ahora, en cuanto al profesorado universitario europeo, Nussbaum desarrolla una argumentación crítica porque considera que no existe en este cuerpo docente una preparación pedagógica conveniente $\mathrm{y}$, además, les atribuye un trato distante $\mathrm{y}$ jerárquico. Estas características las contrapone al profesorado estadounidense quien, según sus argumentos, recibiría una mejor preparación pedagógica, estaría más habituado al trabajo con grupos reducidos de estudiantes y mostraría un trato más próximo en comparación con sus homólogos europeos. Además, afirma que "la presión por lograr el crecimiento económico ha llevado a muchos líderes políticos de Europa a reformular la totalidad de la educación universitaria en términos orientados hacia el crecimiento" (p. 169). Aunque de sus palabras podemos deducir que se refiere a la reforma del Espacio Europeo de Educación Superior, iniciada a partir de la Declaración de Bolonia, la autora solo menciona una vez el Proceso de Bolonia y en una nota a pie de página. Es un contenido no tratado que, quizás, la lectora o el lector pueden echar en falta, ya que Nussbaum señala varias referencias sobre las transformaciones que están desarrollándose en las universidades europeas, sobre las 
medidas para "demostrar el impacto de las investigaciones" (p.169) y sobre el avance silencioso hacia el modelo de crecimiento europeo. La autora se detiene en el caso británico para explicar algunos detalles sobre el sistema de evaluación de los proyectos de investigación citando un articulo de Stefan Collini quien "presenta una crítica demoledora sobre los efectos de este nuevo modelo para las humanidades" (p. 172) y también detalla algunos aspectos relevantes de la situación de las universidades de la India para llegar al caso de Estados Unidos y afirmar que "incluso en los Estados Unidos, que parecía ser un gran baluarte de las humanidades, detectamos señales de peligro" (p. 176).

Antoni Furio (2010), profesor de la Universitat de Valencia, argumenta que no es cierto que no haya otra salida para la universidad que la mercantilización, que tanto ocupa y preocupa a los agentes vinculados con el sistema universitario, y que tendrá que reinventarse y mantener su conciencia crítica para seguir existiendo como hasta ahora la hemos entendido.

\section{Impulsar el desarrollo humano integral}

El punto de partida de la reflexión crítica para responder a la pregunta ¿por qué la democracia necesita de las humanidades? es el reconocimiento de la crisis silenciosa en el lugar que hoy ocupan las humanidades en la educación superior y su respectivo corolario para la vida pública del ciudadano. Martha Nussbaum alerta sobre la existencia de esta crisis, "debido a que las naciones sedientas de ingresos" (p.11) para mantenerse en la dinámica de la globalización y otras en vía de desarrollo que forzosamente intentan a costa de todo insertarse en la misma, deciden desechar a partir de la apuesta por el modelo de desarrollo económico, la formación de otras aptitudes o capacidades propias en sus ciudadanos, que disten de este modelo. El recorte en los presupuestos destinados a las disciplinas humanistas, "produce la gran erosión de las cualidades esenciales para la vida misma de la democracia" (p. 11). Tres razones acompañan esta discusión:

Primero, destacamos la necesidad de escuchar, reflexionar y agenciar el paradigma de desarrollo humano en el ámbito educativo, como una manera de responder a los gritos silenciosos de esta crisis, que ha llegado a todos los espacios geográficos y que influye en el desarrollo de las capacidades humanísticas, tales como la imaginación, el reconocimiento del otro, la experimentación personal de la vulnerabilidad y la fragilidad propia de cualquier sujeto humano.

En segunda instancia y sin desconectarse del anterior, asumimos la apología a la praxis pedagógica soportada desde las artes y las humanidades, gestora del pensamiento crítico indispensable para la construcción de la democracia y la ciudadanía mundial, con lo cual no se desconoce a las ciencias experimentales, ni se pretende ahondar el debatido abismo entre humanidades y ciencias. Se trata entonces de desarrollar las competencias científico-humanísticas como una unidad en el sujeto, 
que de cara a la racionalidad economicista y pragmática de la globalización y el neoliberalismo, movilice en los nuevos sujetos, drásticos cambios sobre este modelo que adiestra a las generaciones presentes como máquinas utilitarias y que pareciera responder como única alternativa posible a las lógicas del mercado; en cuanto educar en el paradigma de desarrollo humano, es agenciar un ciudadano con civilidad internacional.

$\mathrm{Y}$ en tercera medida, declaramos que el trabajo en torno a las humanidades hoy por hoy no puede estar lejos del mundo de la vida, si quiere ser efectivo y socialmente pertinente. Por tanto, como ya se ha indicado, su punto de partida ha de ser el acercamiento a las historias de vida de los estudiantes, sus experiencias, sus narraciones, su particularidad, lo cual permite comprender y construir una ciudadanía activamente democrática, despojada de entrada de las metateorizaciones de la racionalidad especulativa que ha acompañado doctrinalmente a las humanidades.

\section{Educar en humanidades}

Hemos de afrontar cuestionamientos como ¿Qué tan democrática y participativa es la vida cotidiana de nuestros ambientes educativos? ¿Enseñamos a tomar decisiones libres desde la responsabilidad y las implicaciones civiles y sociales? ¿Por qué se hace difícil conservar las instituciones democráticas basadas en el respeto y en la protección igualitaria de la ley? ¿Educar para la renta o para la democracia? Tales preguntas, desde la perspectiva del paradigma de desarrollo humano, han de abordarse en el ámbito educativo superior considerando el conjunto y complejidad que salvaguarda, desarrolla y potencia en el sujeto, las libertades políticas, los servicios económicos, los servicios sociales, las garantías de transparencia, en cuanto el respeto a estos derechos y oportunidades, contribuye a mejorar la capacidad general de una persona y a complementarse mutuamente. (Sen, 2000, 27) Así, lo que se pretende es abogar por el desarrollo de las capacidades humanas desde la propia libertad del sujeto, en tanto agencia su propio destino e historia.

Ahora, ante la pregunta ¿cómo se construyen los sujetos humanos? reconocemos que ya no son suficientes las respuestas metafísicas, ni la retórica enciclopedista, porque la actualización de la formación en humanidades ha de desarrollar la capacidad de escuchar y acompañar la historia de vida y narrativa del otro, en condición desprevenida y no estandarizada, es decir, reconocer las particularidades y la pluralidad en la diversidad con la que cada cual experimenta la vida. No es posible el desarrollo de la democracia si ésta no se constituye desde un sujeto demócrata, humanista, sujeto de civilidad mundial.

En este sentido, la formación socio humanista ha de considerar:

- Que es preciso revisar los procesos pedagógicos y los contenidos curriculares, para que el cultivo de la conciencia crítica persiga desarrollos significativos y pertinentes para los estudiantes. Es apremiante partir del mundo de la vida; de las experiencias 
vivenciales; de las historias de vida; de un análisis crítico de la realidad; del afrontamiento de los conflictos; de la cultura dialógica; de la capacidad de resiliencia; de procesos comunicativos; del desarrollo de las artes, de la autoconstrucción de la democracia en un clima de confianza con el otro, para hacer posible, de modo efectivo, la convivencia y el respeto a la dignidad humana consagrada en los derechos humanos.

- Frente a las políticas educativas centradas en la formación técnica y capacitación laboral que malinterpretan o reducen el sentido del desarrollo humano integral, como simple desarrollo de la técnica y el trabajo, consideramos que los propósitos de formación socio-humanística en pregrado y postgrados son insoslayables y para nada distantes a la condición científica, con lo cual se advierte otro modo posible al que el capitalismo y la racionalidad instrumental han convertido las ciencias.

- Superar los modelos pedagógicos tradicionales centrados en la transmisión y repetición de contenidos, incorporando el juego, la lúdica y las actividades artísticoculturales a través de programas de música, literatura, cine, concursos de fotografía, video-testimonio, con lo cual se potencie el pensamiento crítico, la capacidad imaginativa y la sensibilidad moral, espiritual y estética en cualquier sujeto.

- Aplicar estrategias didácticas y pedagógicas que favorezcan la autorreflexión, tales como el practicum reflexivo y el modelo didáctico pedagógico de la Composición y privilegiar las investigaciones con enfoques holístico, complejo y biográfico.

- El fortalecimiento en la participación activa en movimientos cívicos que abordan causas democráticas, de ciudadanía mundial y correlación ambiental.

- Acompañar, entre otras situaciones la manera como cada sujeto resuelve sus conflictos; la correlación con sus redes sociales, entendidas éstas desde la familia hasta las emergentes en el ciberespacio; la sensibilidad hacia el otro y el respeto a las diferencias; así como el cultivo de la experiencia espiritual liberada de fundamentalismos.

¿Por qué la democracia necesita de las humanidades, del arte y de la imaginación creativa sin ánimo de lucro? Desde las cuestiones aquí expuestas, las escuelas que asumen las tareas de formar ciudadanos críticos y demócratas deben privilegiar el cultivo de:

- La capacidad de ver el mundo desde la perspectiva del otro, especialmente de quienes se han considerado tradicionalmente "inferiores".

\footnotetext{
${ }^{4}$ Es un prototipo de sistematización del proceso investigativo para el aprendizaje basado en estudio de casos, problemas o proyectos de intervención. Su constitutivo obedece a ocho elementos que parten de uno hechos, los cuales se convierten en evento o acontecimientos. Una vez definido los hechos se le da cursos a los demás elementos: propósitos, problema, conceptos, método, forma, solución y analogía.
} 
- La capacidad de comprender que la debilidad y la impotencia no son situaciones de indignidad, sino oportunidades para la cooperación y la reciprocidad.

- La capacidad de desarrollar interés por los demás.

- La capacidad de superar la tendencia de alejamiento o indiferencia ante las minorías.

- La capacidad de apoyarse en contenidos reales y concretos para el respeto a las diferencias.

- La capacidad de asumir las propias responsabilidades, en los distintos órdenes de la vida.

- La capacidad de promover el pensamiento crítico y el coraje para expresarlo.

En resumen, los argumentos hasta aquí presentados, el paradigma de desarrollo humano integral, estaría orientado en la agencia de tres capacidades fundamentales para el cultivo de la humanidad: a) pensamiento crítico, b) ciudadanía global, y c) comprensión imaginativa.

\section{Cultivar el pensamiento crítico}

Se parte de la pregunta ¿cómo generar la apertura de un pensamiento crítico, complejo y racional en el contexto de una sociedad altamente tecnificada, con estándares competitivos de una economía funcional, que tiene la tendencia homogénea de reducirlo todo a una racionalidad economicista, masificada y que favorece las élites de poder? Siguiendo los planteamientos de Nussbaum, se propone:

- Plantear las cátedras de humanidades desde escenarios del mundo de la vida.

- Establecer competencias en todas las profesiones, que no ignoren la imaginación, la creatividad y el compromiso ciudadano.

- Incentivar espacios literarios, la producción de textos escritos, debates críticos con el reconocimiento de la propia identidad.

- Fortalecer las cátedras de comunicación y liderazgo en el ámbito de la formación profesional.

- Incluir espacios didácticos para la historia oral, talleres de fotografía, conversatorios literarios, producción de documentales, caricatura, el dibujo, la plástica y la música.

- Incentivar la imaginación y la argumentación mediante el uso de las redes juveniles y sociales, para desarrollar la capacidad crítica e influir en la solución de los problemas locales y nacionales. 


\section{Conducir hacia una Ciudadanía global}

La pregunta ¿cómo construir una ciudadanía desde lo multicultural? incluye replantear el modo de ser y estar en el mundo necesariamente desde nuevas cosmovisiones con relación a la forma de ver, comprender y asumir al otro en su realidad teniendo en cuenta algunos elementos que puedan motivar las prácticas sociohumanistas en la universidad:

- Concebir la tarea educativa en torno a las humanidades como acogida de la alteridad. Frente a la unidimensionalidad y la racionalidad centradas en el afán de lucro, se requieren nuevas formas de concebir al otro e interpretar el mundo, desde las cuales sea posible concebir la condición humana como una dinámica de posibilidades, situación que presupone escuchar e incorporar la mirada del otro desde su realidad.

- Desde las actitudes es posible comprender la condición humana y desde una perspectiva social, superar el divorcio entre lo mental y el mundo de la vida, en el contacto con las situaciones propias de la cotidianidad.

- ¿Cómo construir un espacio que permita la participación en un diálogo respetuoso y cooperativo? Las prácticas sociales y valores como la solidaridad, la subsidiaridad y la cooperación no son patrimonio de las instituciones, pero son elementos identitarios que permiten construir climas de convivencia más sinérgicos y hacen posible combatir el paradigma del individualismo, el culto a la renta y la exclusión social.

- La tarea de las humanidades es deconstruir algunas tradiciones, paradigmas, imaginarios, prejuicios, que fortalecen actitudes etnocentristas, donde el otro no existe; para visualizar un mundo donde se permita reconocer y valorar, respetar y tolerar las diferentes identidades sociales que coexisten en el mundo, en donde se pase de la teoría a la praxis como autoconstrucción de la ciudadanía democrática y donde sea posible convivir desde el pluralismo y la biodiversidad presente en el planeta.

\section{Generar procesos de comprensión imaginativa}

¿Por qué las artes en la educación superior? El desarrollo de la imaginación narrativa permite formar ciudadanos con actitudes democráticas y comprensión de la historia humana. Esto en el entendido que el cultivo de las artes y la lúdica desde la infancia, han de enseñar la vida con otros ojos, los ojos de la interioridad, lo cual desarrolla la mente abierta, flexible y creativa, que se cultiva desde la literatura, las artes y humanidades. Su corolario:

- La relación con la adultez y el ciudadano democrático se da en la medida que la imaginación tiene implicaciones de alteridad, superando el narcicismo y que en la 
formación ciudadana conduce a racismos y manejos del poder de manera dictatorial.

- Formar en el poder corresponsable a los nuevos profesionales, haciendo de su ejercicio práctico algo diferente, desde la resolución de dilemas propios e inherentes a su cargo disciplinar. Así, se reafirma la coexistencia en la sociedad de sujetos dispuestos a vivir con los demás en condiciones de respeto mutuo y reciprocidad.

- El arte como autoría permite compartir un mundo de subjetividad, posibilita compartir la historia personal, como una forma de mantener la vida. El arte como un lenguaje de pensamiento divergente, de relaciones difusas, supera la herencia del pensamiento occidental en su afán de estandarizar y unificar un solo discurso. No se puede entender el arte desde una racionalidad binaria, en cuanto el arte funciona con otras lógicas más borrosas, difusas e imprevisibles, lo cual favorece el cultivo de los giros epistémicos y los lenguajes emergentes.

Hoy es claro el divorcio entre las destrezas profesionales y las habilidades artísticas. Es tiempo de recuperar un territorio de competencias científicas humanizadas, en torno a:

- la capacidad de argumentar reflexivamente,

- la capacidad de dialogar en la pluralidad,

- la capacidad del trabajo en equipo, que permita la construcción del conocimiento de manera colectiva,

- la capacidad ética,

- la capacidad del pensamiento crítico,

- la capacidad de ubicarse históricamente,

\section{Conclusiones}

Las observaciones, generales, derivadas del seminario, comprometen a la Universidad Santo Tomás y toda su comunidad educativa, desde la formación integral, en cuanto a la re-significación de las humanidades, como desafío pedagógico que invita a rediseñar y actualizar el currículo permanentemente.

La reflexión en torno a la investigación de Nussbaum, sitúa la realidad de amenaza para las artes y las humanidades en un contexto capitalista que tiende cada vez más a instrumentalizarlas y defender este escenario como el único posible, el cual fractura fina y silenciosamente la ciencia y las humanidades. Frente a esto, la reconstrucción de estas últimas se debe adaptar muy rápidamente a las necesidades próximas, para pensarse, pero sobre todo articularse desde un modo de ser distinto al que la tradición de la episteme y el sentido de la tecné la ha llevado como desligada de la realidad práctica. Se trata de afrontar inteligentemente en los currículos y prácticas pedagógicas de la Universidad Santo Tomás, los nuevos retos que así se le exigen a los 
departamentos y unidades académicas responsables de las humanidades. Éstas al recomendar la renovación de los currículos, han de orientar que para nada distan de las ciencias experimentales, en este sentido se trata de formar competencias humanistas de las ciencias en los nuevos candidatos educables en este momento de "crisis planetaria".

La historia económica unidimensional ha ubicado al ser humano en el contexto latinoamericano sólo como sujeto competente para el mercado laboral y ha tomado para sí la vulnerabilidad y fragilidad como algo prescindible y que se debe obviar por el afán de lucro. Entonces, el trabajo fuerte de las artes y las humanidades en los centros de educación superior, es la agencia de las capacidades u oportunidades del sujeto, que para nada renuncian al derecho de reconocer a través de la imaginación la vulnerabilidad y fragilidad de la contingencia de la condición humana, para esto la implementación de clubes que trabajen con temas específicos y el estudio de casos al interior del aula, aunado a los voluntariados de la extensión social, han de sensibilizar al sujeto educable en condiciones de marginalidad y pobreza no sólo de carácter económica sino mental.

Es insostenible la defensa argumentativa de la democracia, si en sentido práctico al interior de las aulas y centros educativos no hay en ellas las posibilidades reales para el sujeto demócrata. Esto exige a la educación superior que el ejercicio pedagógico y las relaciones de poder por parte de los distintos actores que se desempeñan en los espacios académicos institucionales, permita la participación de sujetos democráticos en su seno y la expresión desde la diversidad cultural. Así en la búsqueda apremiante de un ciudadano mundial: el pensamiento crítico, la capacidad de pensar por sí mismo, el dar valor y respeto a la cultura internacional, son exigencias para este proyecto de resignificación que supere el sofisma del sujeto autómata.

Las artes y humanidades no pueden estar lejos del mundo de la vida, su punto de partida son las existencias reales de los actores, lo cual convierte el escenario pedagógico en un constante diálogo desde distintas narrativas, y que han de estar lejos de los fundamentalismos y dogmatismos de las verdades absolutas, porque cada sujeto se ejercita como actor activo de su propio aprendizaje, con mirada y pensamiento complejo y capaz de dar sentido a la multiplicidad y diversidad de experiencias humanas en su relación con el mundo y con las diversas formas de convivencia. En este sentido, el ejercicio pedagógico se ha de convertir en diáfano laboratorio de racionalidad y pluralidad, que permita multiplicar las experiencias de enseñanzaaprendizaje, pero por sobre todo en el campo de la investigación formativa desde un modelo colaborativo que permita pensar, sentir y vivir de manera razonable, para fortalecer la convivencia y la diversidad de relaciones en sociedades más equitativas. 


\section{Referencias bibliográficas}

BORRERO, C. (2008). La Universidad, estudios sobre sus origenes, dinámicas y tendencias. Tomo II. Bogotá: Editorial Pontificia Universidad Javeriana.

BOK, D. (2010). Universidades a la venta. La comercialización de la educación superior. Valencia: Publicacions de la Universitat de Valencia.

CORNWELL, G. Y STODDARD, E. (2000). Global Multiculturalism: Comparative Perspectives on Ethnicity, Race, and Nation. Rowman \& Littlefield: United States of America.

FURIO, A. (2010). El futuro de la universidad. PASAJES Revista de pensamiento contemporáneo: Universidad en transformación. Otoño 2010. Valencia: Publicacions de la Universitat de Valencia.

MUNCH, R. (2010). Bolonia, o la capitalización de la educación. PASAJES Revista de pensamiento contemporáneo: Universidad en transformación. Otoño 2010. Publicacions de la Universitat de Valencia.

NAVARRO N. (2006). El seminario investigativo alemán. Medellín: Programa de Desarrollo Pedagógico Docente.

NUSSBAUM, M. (2005). El Cultivo de la Humanidad. Una defensa clásica de la reforma en la educación liberal. Barcelona: Paidós.

NUSSBAUM, M. (2010). Sin Fines de Lucro. Por qué la democracia necesita de las humanidades. Buenos Aires: Katz, Editores.

SEN, A. (2000). Desarrollo y libertad. Bogotá: Planeta.

\section{Correspondencia con los autores}

Jaime Andrés Argüello Parra

Doctor en Pedagogía, UNAM (México) - University of Lodz (Polonia), (2012)

Magister en Educación, Universidad santo Tomás, Bogotá

Licenciado en Ciencias de la Educación, Universidad de la Salle Bogotá

Docente Investigador, Universidad Santo Tomás de Colombia

mouneriano@yahoo.es

Oscar Javier Cabeza Herrera

Magíster en Bioética, Universidad El Bosque, (2006)

Especialista en Cultura Política y Educación, Universidad de Pamplona, (2001)

Licenciado en Filosofía e Historia, Universidad Santo Tomás (2001)

Docente Investigador, Universidad Santo Tomás de Colombia

oscar.cabeza@hotmail.com 
Roberto Alonso Cardona Ospina

Magíster en Pedagogía. Universidad Industrial de Santander - UIS (2009)

Especialista en Docencia Universitaria. Universidad Santo Tomás (2008)

Licenciado en Filosofía. Corporación Universitaria Minuto de Dios (1996)

Docente Investigador, Universidad Santo Tomás de Colombia

roalcaos@gmail.com

Martín Emilio Hernández Manrique

Licenciado en Filosofía y Ciencias Religiosas. Universidad Santo Tomás, (2000)

Docente Investigador, Universidad Santo Tomás de Colombia

marehem@gmail.com

Dénix Alberto Rodríguez Torres

Doctorando en Educación. Universidad de Wiener (2012)

Magíster en Educación. Universidad Santo Tomás (2010)

Licenciado en Filosofía. Corporación Universitaria Minuto de Dios (1996)

Docente Investigador, Universidad Santo Tomás de Colombia

denixvirtual@gmail.com 